\title{
The Committees of the Protocol
}

\author{
K A T Y H A Y A R D
}

\subsection{Introduction}

The implementation of the Protocol is governed by three UK-EU institutions established by the Withdrawal Agreement (WA). The Joint Committee (JC) is to oversee the implementation and application of the WA and the Protocol. ${ }^{1}$ The Specialised Committee on the Implementation of the Protocol on Ireland and Northern Ireland (INISC) is to facilitate and administer the Protocol. ${ }^{2}$ The Joint Consultative Working Group (JCWG) is for the 'exchange of information' and 'mutual consultation' between the $\mathrm{UK}$ and the $\mathrm{EU},{ }^{3}$ which then informs the work of the INISC. The rules of procedure for the JC and all six Specialised Committees are set out in Annex VIII of the WA. Each body comprises, and is co-chaired by, representatives from the $\mathrm{EU}$ Commission and the UK government. Aside from governance, they are important mechanisms for formal and informal dialogue between the two sides. This chapter summarizes the constitution, remit and operation of each of them, as set out in the WA and as they operated in practice during the first months of their establishment.

\subsection{The Joint Committee}

\subsubsection{The Formal and Informal Joint Committee}

The JC is the only decision-making body overseeing the WA, drawing on recommendations from the Specialised Committees. The JC will make all its decisions and recommendations 'by mutual consent'. ${ }^{4}$ It follows that the JC cannot act if either the UK or the Commission is not in agreement. Almost immediately after it came into effect on 1 February 2020, the

\footnotetext{
1 Art 164 WA.

2 Protocol Art 14.

3 Protocol Art 15.

4 Art 166(3) WA.
} 
Protocol was a source of tension in the UK-EU relationship precisely because it required agreement and co-operation between them. The JC has been key to enabling progress to be made in such circumstances, but not in the way strictly envisaged by the WA.

The JC is to be chaired by members of the EU Commission and the UK government, although they can designate high-level officials to act as their alternates. ${ }^{5}$ The fact that the JC is led by senior political representatives from the two sides is a double-edged sword. The first co-chairs of the JC were European Commission Vice-President Maroš Šefčovič and the UK Chancellor of the Duchy of Lancaster, the Rt Hon Michael Gove. Lord Frost, Prime Minister Johnson's chief negotiator for exiting the EU (July 2019-January 2020) and subsequently chief UK negotiator in the UK-EU Trade and Cooperation Agreement (TCA) negotiations in 2020, was made Minister of State in the Cabinet Office and (unusually) a full member of the UK Cabinet on 1 March 2021. He replaced Minister Gove as co-chair of the JC. ${ }^{6}$

The JC is to meet at least once a year, and at the request of the EU or the UK. The first meeting of the JC was held on 30 March 2020 and in the intervening twelve months it had five further official meetings, plus an extraordinary meeting (10 September 2020) in response to the UK Internal Market (UKIM) Bill in which the UK government proposed to equip its ministers to breach the obligations of the Protocol. In a context of high stakes over the TCA negotiations and the Protocol implementation, the political standing of the co-chairs enabled them to opt to meet informally in so-called political meetings. The first such meeting, on 7-8 December 2020, allowed the two to negotiate a breakthrough (and, in the UK case, resulted in the withdrawal of the offending UKIM clauses). The joint statement from Minister Gove and Vice President Šefčovič after that meeting paved the way for the decisions to be approved in the official meeting of the JC they chaired eleven days later. ${ }^{7}$ Informal meetings between the co-chairs remained important in the first few months of implementing the Protocol, especially against the backdrop of a UK-EU dispute. ${ }^{8}$

${ }^{5}$ Its Secretariat is composed of an official of the European Commission and an official of the UK government.

${ }^{6}$ And the Partnership Council of the TCA, also co-chaired by V-P Šefčovič.

7 Summary Minutes, Fifth Regular Meeting of the JC, 17 December 2020.

8 These meetings are usually followed by joint statements - in contrast to the formal meetings of the JC, for which the Commission and the UK government issued separate statements (at least up to May 2021). 


\subsubsection{Dispute Settlement and the Joint Committee}

Within two days of Lord Frost's appointment, the UK government announced unilateral action to extend the 'grace periods' for the Protocol's implementation. ${ }^{9}$ In Lord Frost's call to Vice President Šefčovič later that day (classed by the UK government press release as their 'first meeting'), he described the measures as 'the minimum necessary steps to allow time for constructive discussions in the Joint Committee'. ${ }^{10}$ The notion that in an informal 'meeting' a co-chair can justify action that their counterpart would not consent to in an official meeting represents a peculiar use and interpretation of the role of the JC. The UK co-chair is far freer than their EU counterpart (the Commission being very different from a sovereign government) to engage in such game-playing. This can be problematic, not least given the importance of the JC as the forum for dispute resolution.

Resolving disputes by consensus is a core function of the JC. Each party may refer 'any issue relating to the implementation, application and interpretation' of the WA to the JC. ${ }^{11}$ In the event of this happening, ' $\mathrm{t}$ ] he Union and the United Kingdom shall endeavour to resolve any dispute regarding the interpretation and application of the provisions of this Agreement by entering into consultations in the Joint Committee in good faith, with the aim of reaching a mutually agreed solution'. ${ }^{12}$ If no resolution to a dispute sent to the JC is found within three months, the issue will be referred to the arbitration panel, whose decision will be final and binding. ${ }^{13}$ In matters where the arbitration panel requires an interpretation of EU law, the arbitration panel must ask for the European Court of Justice's ruling on the matter. It is notable that when the EU commenced legal proceedings against the UK for breaching the substantive provisions of the Protocol in September 2020 and March 2021, the JC co-chairs resorted to informal meetings. The behind-scenes negotiations and political bargaining have thus been shown to play an important, if unofficial, part in the dispute settlement role of the JC.

9 Statement by the Secretary of State for NI, Brandon Lewis, to the House of Commons on the 'NI Protocol: Implementation', 3 March 2021, HCWS819.

${ }^{10}$ UK Government Press Release, Lord Frost call with European Commission Vice President Maroš Šefčovič, 3 March 2021.

11 Art 164(3) WA.

12 Art 169(1) WA.

13 Art 170 WA; see also Chapter 5. 


\subsubsection{The Operation of the Joint Committee}

Officially, the JC is to hold its meetings alternately in Brussels and London. In practice, it met in virtual and in hybrid form (a mix of inperson and videoconferencing) during the Covid-19 pandemic. Where appropriate and by decision of the co-chairs, experts or others may be invited to attend meetings of the JC. Following a UK government commitment in the New Decade, New Approach document, which saw the restoration of power-sharing in Northern Ireland in January 2020, representatives from the Northern Ireland Executive are invited to be part of the UK delegation in meetings of the JC. ${ }^{14}$ These invitations will happen only in instances where the Committee concerned is discussing Northern Ireland-specific matters and which are also attended by the Irish government as part of the EU's delegation. ${ }^{15}$ Representatives from EU member states are also allowed to attend official JC meetings. ${ }^{16}$

According to the JC's rules of procedure, the provisional agenda for each meeting of the JC is to include items requested by the Union or the UK. The agenda for the first six regular meetings typically saw a stocktake on the work of the Specialised Committees and an update on WA implementation. It became evident by late 2020 that the Protocols on Citizens' Rights and on Ireland-Northern Ireland would demand the most attention from the JC, given the evolving conditions and the emerging issues from these that the JC must oversee.

\subsubsection{The Powers of the Joint Committee}

The UK and the EU are obliged to implement the JC's decisions, which will have the same legal effect as the WA itself. ${ }^{17}$ At no point is there an obligation for the UK or the European Parliament to discuss such issues, and neither will be asked or required to ratify decisions taken by the JC as a rule. ${ }^{18}$ The

${ }^{14}$ New Decade, New Approach, 8 January 2020, p 47.

${ }^{15}$ In practice, the two junior ministers (DUP and Sinn Féin) at the Executive Office have attended JC meetings more frequently than the First and Deputy First Ministers themselves.

${ }^{16}$ For example, the third JC meeting on 28 September 2020 was attended by EU memberstate representatives. Gove, statement to the House of Commons on JC Meeting, 29 September 2020, Hansard, Vol 681, HCWS476. This is a sign of the concern across EU member states about the implementation of the Protocol even as the TCA was being negotiated.

17 Art 166 WA.

18 Unless the JC makes a decision that constitutes an amendment or replacement to part of the WA (pursuant to s 25(2) of the Constitutional Reform and Governance Act 2010), see 
scope and effect of the Protocol will evolve under the oversight of the JC. This will happen in three main ways. First, until the end of 2024, the JC has the authority under Article 164(5) of the WA to adopt decisions amending it (including the Protocol), 'provided that such amendments are necessary to correct errors, to address omissions or other deficiencies, or to address situations unforeseen when this Agreement was signed, and provided that such decisions may not amend the essential elements of this Agreement.' ${ }^{19}$ Second, Protocol Article 13(3) provides for dynamic alignment to specific areas of the EU acquis. Where planned Union acts amend or directly replace EU acts listed in the Protocol, they will be automatically updated and apply in Northern Ireland. In principle, they cannot be blocked by the UK. Third, under Article 13(4) of the Protocol, the JC will decide whether a new EU law which falls within the scope of the Protocol should apply in Northern Ireland. The procedure for this is that the EU informs the UK of such a newly adopted act, initially through the JCWG to allow the UK to consider it, with clarification and consultation being offered through that channel as needs be. The debate in the JC will centre on whether such acts are necessary for the 'proper functioning of the Protocol'. The JC shall then either add the new act to the relevant Protocol annex or, where the UK objects, 'examine all further possibilities to maintain the good functioning of this Protocol and take any decision necessary to this effect ${ }^{20}$ This second sub-paragraph grants considerable power to the JC in influencing how the Protocol functions. In the absence of a decision by the JC, the EU may take 'appropriate remedial measures'.

\subsubsection{The Remit of the Joint Committee}

The JC has a broad and substantial remit. This includes deciding the tasks of the Specialised Committees, supervising their work, establishing new Specialised Committees, and disestablishing existing Specialised Committees. It is also charged with 'preventing problems', resolving disputes and considering 'any matter of interest' relating to the WA. And it must issue an annual report on the functioning of the WA (something the Secretariat failed to do by the 1 May deadline after its

Lord Keen of Elie, Lords Spokesperson (Ministry of Justice), House of Lords Debate on the UK-EU JC, 20 March 2019, c1436.

19 In May 2020 the Commission proposed the addition of eight acts to Annex 2 of the Protocol. Those which were accepted by the UK were approved in the second meeting of the JC on 12 June 2020.

20 Protocol Art 13(4), emphasis added. 
first year). ${ }^{21}$ With respect to the Protocol, the JC was tasked with particular responsibilities to complete during the transition period. This included setting the criteria for goods entering Northern Ireland from outside the EU (including GB) to manage the risk posed to the Single Market. ${ }^{22}$ The fifth formal meeting of the JC included several decisions about the operationalization of the Protocol, plus a set of time-limited unilateral declarations which allowed 'grace periods' on the full application of EU rules on heavily regulated areas, including medicines and chilled meat products.

The temporary yet all-important nature of these arrangements was shown in the fact that, six months later, in June 2021, the Commission announced a package of measures aimed at addressing some of the challenges that had arisen for movement across the Irish Sea under the Protocol. This included agreeing to a further extension of the grace period for the movement of chilled meats from GB to Northern Ireland until 30 September 2021, proposing an amendment to EU law on medicines to ensure the continued long-term supply of medicines from GB to Northern Ireland, and facilitating the movement of guide dogs accompanying travellers from GB to Northern Ireland. ${ }^{23}$ The fact that this was not, however, officially a joint decision by the JC reflected the strains in the political relationship and the consequent tendency during the early implementation of the Protocol to act unilaterally or (at best) in parallel, rather than jointly through the JC despite its considerable powers.

The JC has six particular areas of responsibility: defining 'at risk' goods $;{ }^{24}$ the operation of the UK Trader Scheme; ${ }^{25}$ application of value

${ }^{21}$ Rule 14, Rules of Procedure, Decision No 01/2020 of the JC established by the Separation Agreement of 18 December 2020 Adopting the Rules of Procedure of the JC.

22 Art 5(2) of the Protocol: 'Before the end of the transition period, the JC shall by decision establish the criteria for considering that a good brought into NI from outside the Union is not at risk of subsequently being moved into the Union.' The EU's Common External Tariff has to be paid on those goods that are considered to be 'at risk'; this should be reimbursed if it is proven that those goods stayed within the UK. Whether goods entering NI via GB are 'at risk' or not, they are all subject to customs controls and paperwork, and, potentially, regulatory checks.

${ }^{23}$ European Commission, Press Release, 'EU-UK Relations: Solutions Found to Help Implementation of the Protocol on Ireland and Northern Ireland', 30 June 2021, https://ec .europa.eu/commission/presscorner/detail/en/ip_21_3324. This package of measures is discussed further in 'Update: Developments from July 2021 to September 2021' at the front of this book.

${ }^{24}$ According to Art 5(2), the JC may amend at any time its decisions adopted relating to 'at risk' goods.

25 The JC co-chairs informally agreed the terms of the UK (Trusted) Trader Scheme on 8 December; the JC is to keep this under review and can enact an 'emergency brake' if deemed necessary. 
added tax (VAT) and excise rules; ${ }^{26}$ agricultural support scheme limits; ${ }^{27}$ working arrangements for EU presence in $\mathrm{NI} ;{ }^{28}$ proposing the alternative for Articles 5-10 of the Protocol if the Northern Ireland Assembly withholds its consent for their continued application. ${ }^{29}$ All these point to the breadth and significance of the future decisions of the JC for Northern Ireland.

\subsubsection{The Monitoring and Reviewing Role of the Joint Committee}

The JC carries extraordinary responsibility when it comes to keeping under constant review three dynamic processes that are very consequential for the UK and Ireland. First, relating to the movement of goods to and from Northern Ireland, it is to review the facilitation of trade within the UK:

Having regard to Northern Ireland's integral place in the United Kingdom's internal market, the Union and the United Kingdom shall use their best endeavours to facilitate the trade between Northern Ireland and other parts of the United Kingdom, in accordance with applicable legislation and taking into account their respective regulatory regimes as well as the implementation thereof. The Joint Committee shall keep the application of this paragraph under constant review and shall adopt appropriate recommendations with a view to avoiding controls at the ports and airports of Northern Ireland to the extent possible. ${ }^{30}$

Second, relating to cross-border co-operation on the island of Ireland: 'The Joint Committee shall keep under constant review the extent to which the implementation and application of this Protocol maintains the necessary conditions for North-South cooperation. The Joint Committee may make appropriate recommendations to the Union and the United Kingdom in this respect, including on a recommendation from the Specialised Committee. ${ }^{31}$

${ }^{26}$ According to Art 8, the JC has the competence to review the application of the rules relating to VAT and excise, 'and may adopt appropriate measures as necessary'.

27 Protocol Annex 6.

${ }^{28}$ Protocol Art 12. These arrangements are to be reviewed by the JC 'at the latest [three] years after entry into force and following a request from the Union or the United Kingdom'. See Decision No 6/2020 of the WA JC on arrangements under Art 12(2) of the Protocol.

29 Protocol Art 18; see also Chapter 10 in this volume. This would have to occur within two years, when Arts 5-10 would automatically cease to apply. The JC 'may seek an opinion from institutions created by the 1998 Agreement' before making its recommendation.

${ }^{30}$ Protocol Art 6(2).

${ }^{31}$ Protocol Art 11(2). 
Finally, the JC has the power to review and terminate arrangements arising from its decisions made just before the end of the transition period. These cover 'at risk' goods, the authorization for trusted-trader status and exchange of information in relation to customs and the movement of goods. ${ }^{32}$

If either Party considers there is significant diversion of trade, or fraud or other illegal activities, that Party shall inform the other Party in the Joint Committee by 1 August 2023, and the Parties shall use their best endeavours to find a mutually satisfactory resolution of the matter. If the Parties do not find a mutually satisfactory resolution, Articles 3(1)(a)(ii), 3(1)(b)(ii) and 5 to 8 of this Decision shall cease to apply from 1 August 2024, unless the Joint Committee decides before 1 April 2024 to continue their application. ${ }^{33}$

If they do cease to apply, then the JC shall 'make appropriate alternative provision applicable from 1 August 2024, having regard to the specific circumstances in Northern Ireland and fully respecting Northern Ireland's place in the United Kingdom's customs territory'. Thus, the JC retains a responsibility to meet the objectives of the Protocol at the same time as it is charged with monitoring and reviewing its implementation, making decisions on its scope and evolution, and maintaining dialogue between the UK and the EU.

\subsection{The Specialised Committee on Ireland-Northern Ireland}

\subsubsection{The Operation of the Specialised Committees}

The JC is supported by six Specialised Committees ranging over the gamut of issues relevant for the operation of the WA, co-chaired by senior officials from the EU Commission and the UK government. ${ }^{34}$ Unless the co-chairs decide otherwise, the Specialised Committees shall meet at least once a year, but additional meetings may be held at the request of the $\mathrm{EU}$, the UK or the JC. ${ }^{35}$ The Union and the UK can bring 'any matter directly to the Joint Committee', so the existence of the Specialised Committees is not allowed to slow down a matter that requires a high-level decision. ${ }^{36}$

32 Protocol Art 5.

33 Decision No 2/2020 of the JC [2020/2246] (OJ L 443/2020), Art 9 on 'review and termination'.

34 The other specialized committees are on citizens' rights; the other separation provisions; issues related to the Sovereign Base Areas in Cyprus; issues related to the implementation of the Protocol on Gibraltar; and the financial provisions of the WA.

35 Art 165 WA.

36 Art 165(4) WA. 
The meeting schedule and agenda of the Specialised Committees shall be set by mutual consent. The Specialised Committee on IrelandNorthern Ireland (INISC) met eight times in the first eighteen months of the WA being in effect. For all but one of these meetings, there was no agenda published and where there were statements issued afterwards, these were released separately by the EU Commission and the UK government. The lack of transparency in the operation of the INISC combined with political and media interest in the UK-EU tension over the Protocol meant that there were leaks to journalists from INISC meetings. This had the effect of sending the work of the INISC deeper into the echelons of the Cabinet Office and Commission, and making its formal meetings less frequent than they might otherwise have been. This only intensified the difficulties for Northern Ireland civil servants charged with keeping up with the work of the INISC. Officials from the Northern Ireland Civil Service are present at official INISC meetings at the invitation of the UK government; whether they are kept informed of the background work of the INISC officials is rather more ad hoc. When asked (amid growing political and public tensions over the Protocol implementation in Northern Ireland) in April 2021 for an update on the engagement by the UK and the EU with Northern Ireland stakeholders, including the Executive, and on formal consultation mechanisms to ensure their full participation in the WA institutions, Lord Frost replied that 'representatives of the NI Executive attend[ed] the JC and the Specialised Committee' - meetings that had happened four to eight weeks earlier. ${ }^{37}$

\subsubsection{The Remit of the Specialised Committee on Ireland-Northern Ireland}

The INISC has a broad power to discuss 'any point ... of relevance' to the Protocol that 'gives rise to a difficulty', as raised by either the UK or the EU. It can also make recommendations to the JC as regards the functioning of the Protocol. In so doing, it in turn may receive proposals from the North-South Ministerial Council (covering aspects of policy and governance relating to transport, agriculture, education, health, environment and tourism) and the six North-South Implementation Bodies, which include north-south trade, EU programmes, waterways and food

37 Lord Frost reply to Lord Kinnoull, chair of the Lords EU Committee, on the Protocol on Ireland/Northern Ireland, 28 April 2021, MC2021/05342. 
safety. It should also consider 'any matter of relevance' brought to its attention by designated bodies relating to the implementation of the Protocol's human rights provisions, namely the Northern Ireland Human Rights Commission, the Equality Commission for Northern Ireland, and the Joint Committee of representatives of the Human Rights Commissions of Northern Ireland and Ireland. The most it could do with these proposals and issues would be to 'make recommendations to the Joint Committee' for decisions. ${ }^{38}$

\subsection{Joint Consultative Working Group}

The JCWG reports to the INISC on issues related to the implementation of the Protocol. Its rules of procedure were not drafted until nine months into the transition period. ${ }^{39}$ The JCWG exchanges information and acts as a forum for mutual consultation in respect of the Protocol between the UK and the EU. The focus is on 'planned, on-going and final relevant implementation measures' relating to changes in EU or UK acts covered by the Protocol. It, too, is co-chaired by the EU and the UK and is composed of representatives of the EU and the UK, who carry out its functions under the supervision of the INISC. There is a degree of flexibility in the composition of participants for each JCWG meeting. ${ }^{40}$ The UK government has committed to including 'representatives of the NI Executive as part of the UK delegation to the group. ${ }^{41}$ According to Article 15 and its rules of procedure, JCWG is to meet at least once a month, unless otherwise decided by the EU and the UK by mutual consent. However, its first meeting on Friday 29 January 2021 (a noteworthy day for the Protocol, as it happens) was merely to sign off on its rules of procedure. Its second meeting was not held until 15 April 2021, and no statement or documentation was published in relation to that.

If, as intended, the JCWG meets more frequently than either the JC or INISC, it will form a vital means of communication between officials in

38 Protocol Art 14(e).

39 Council Decision (EU) 2020/1599 of 23 October 2020 on the position to be taken on behalf of the European Union in the Joint Consultative Working Group as regards the adoption of its rules of procedure, OJ 2020 L 365/3.

40 'Where appropriate and by decision of the co-chairs, experts or other persons who are not members of delegations may be invited to attend meetings of the working group in order to provide information on a particular subject' (Rule 3(2)).

41 Letter from Rt Hon Michael Gove to Colin McGrath, MLA, chair of the Committee for the Executive Office, Northern Ireland Assembly, 6 January 2021, MC2020/17995. 
the UK and the EU. Along with this comes the potential for keeping Northern Ireland civil servants informed and connected. This is particularly important given the need for Northern Ireland officials to be aware of the evolving regulatory environment as created by the Protocol. Article 15(7) of the Protocol places an obligation on the EU to communicate the views and information shared in the JCWG to 'the relevant institutions, bodies, offices and agencies of the Union without undue delay'. There is no similar obligation on the UK, despite the obvious need for effective communication on the work covered by the JCWG to institutions, agencies and offices in Northern Ireland.

\subsection{Conclusion}

A House of Lords European Union Committee Report concluded that the effectiveness of the UK-EU committees established under the WA 'will depend on the frequency of their meetings, the flexibility of their remit, senior political representation on both sides, and a mutual commitment to effective communication, appropriate powers, and full accountability'. ${ }^{42}$ The operation of the UK-EU bodies during the transition period and in the first few months of 'Brexit proper' after the transition period ended has revealed chronic inadequacy in all these areas. This marks an inauspicious beginning for these important new UK-EU institutions.

${ }^{42}$ House of Lords, European Union Committee (2019) 'Beyond Brexit: How to Win Friends and Influence People', 35th Report of Session 2017-19. 